\title{
Aplicação de farinha de casca de maracujá em massa alimentícia fresca
}

\author{
Application of passion fruit peel powder in fresh pasta
}

\section{Autores | Authors}

$\bowtie$ Gabriela FOGAGNOLI

Instituto Mauá de Tecnologia (IMT) Programa de Pós-graduação strictu sensu em Engenharia de Processos Químicos e

Bioquímicos CEP: 09061-030

Santo André/SP - Brasil

e-mail: gabrielafogagnoli@gmail.com

Elisena Aparecida Guastaferro

SERAVALLI

Instituto Mauá de Tecnologia (IMT) Departamento de Alimentos e Química São Caetano do Sul/SP - Brasil e-mail: elisena@maua.br

$\triangle$ Autor Correspondente / Corresponding Author

Recebido: Mar. 26, 2014

Aprovado: Ago. 27, 2014

\section{Resumo}

Este trabalho teve como objetivo avaliar a influência da adição de farinha de casca de maracujá e um emulsificante (estearoil-2-lactil-lactato de sódio) nas características de massa alimentícia fresca. Para comparação, uma formulação padrão foi desenvolvida utilizando farinha de trigo, água e emulsificante. Um planejamento fatorial completo $2^{2}$ foi usado para avaliar a influência dos dois ingredientes (variáveis independentes) na taxa de absorção de água durante o cozimento, no aumento de volume, na perda de sólidos e na elasticidade da massa. Variando a concentração de farinha de casca de maracujá de 5,0\% para 8,0\%, houve aumento de $40 \%$ na perda de sólidos e redução de $20 \%$ na elasticidade da massa desenvolvida. Com esses resultados, estabeleceu-se a formulação a ser usada, contendo $0,4 \%$ de emulsificante e $5 \%$ de farinha de casca de maracujá, apresentando na sua composição, em base úmida: 1,34\% de gordura; 9,25\% de proteína; $0,61 \%$ de cinzas; $0,0598 \%$ de sódio; $52,45 \%$ de carboidratos; e 5,22\% de fibras. Amostras de macarrão preparado com as duas formulações (padrão e adicionada de farinha de casca de maracujá) foram oferecidas a provadores não treinados para avaliação sensorial. Os resultados do teste de aceitação não mostraram diferença significativa entre elas $(p>0,05)$ e as duas formulações apresentaram notas entre os termos hedônicos "gostei regularmente" e "gostei muito". O produto final desenvolvido apresentou teor de fibras superior a $3 \%$, podendo ser classificado como fonte de fibras (2,5 gramas de fibras na porção de 80 gramas do macarrão pronto para consumo).

Palavras-chave: Macarrão; Farinha de casca de maracujá; Emulsificante.

\section{Summary}

The aim of this study was to evaluate the influence of passion fruit peel powder and an emulsifier (sodium stearoyl-2-lactylate) on the characteristics of fresh food pasta. For comparative purposes, a control formulation was developed with wheat flour, water and emulsifier. A complete $2^{2}$ factorial design was used to investigate the effects of both ingredients (independent variables) on the rate of water absorption during cooking, pasta swelling, loss of solids and pasta elasticity. Varying the concentration of passion fruit peel powder from 5.0 to $8.0 \%$ increased the loss of solids by $40 \%$ and reduced the elasticity of the pasta by $20 \%$. A formulation was thus developed with $0.4 \%$ emulsifier and $5 \%$ passion fruit peel powder, showing the following composition on a wet weight basis, $1.34 \%$ fat; 9.25\% protein; $0.61 \%$ ash; $0.0598 \%$ sodium; $52.45 \%$ carbohydrates and $5.22 \%$ fibre. A sensory evaluation for consumer acceptanceof the pasta prepared with both formulations (control and with passion fruit fibre) showed no significant differences between the two $(p>0.05)$. The overall acceptance of both samples resulted in test scores between "like slightly" and "like moderately" on a 9-point hedonic scale. The resulting product presented more than $3 \%$ fibres and could therefore be classified as a source of fibres (2.5 grams of fibres per 80 gram portion of pasta ready for consumption).

Key words: Pasta; Passion fruit peel powder; Emulsifier. 


\section{Introdução}

O Brasil, por influência da imigração italiana, tornou-se um dos grandes produtores e consumidores de massas alimentícias. Essa popularidade do produto se deve ao fato de ser produzido com tecnologia simples, de baixo custo, de fácil preparo, atrativo e versátil, disponível nos mais variados formatos, tamanhos e cores, com vida de prateleira relativamente longa e por não requerer embalagens sofisticadas (GUERREIRO, 2006).

O processamento de massas alimentícias frescas normalmente é realizado seguindo-se as etapas mistura, amassamento, laminação, corte, secagem e empacotamento (GUERREIRO, 2006). Os ingredientes utilizados são: farinha de trigo, sendo a mais indicada para fabricação de macarrão a semolina de trigo Durum que, por ter custo elevado, é substituída pela farinha especial; água, que deve ser clara, sem gosto ou odor, sem microrganismos; emulsificante, estearoil-2-lactillactato de sódio, cuja função é melhorar a qualidade da massa e reforçar o glúten. Entretanto, com o cozimento, ocorre desnaturação dessas proteínas e o emulsificante reduz a perda do amido para a água de cozimento durante a gelatinização, provocando uma diminuição do tempo de cozimento e favorecendo assim a obtenção de um produto com melhor sabor, textura e menor pegajosidade (MENEGASSI e LEONEL, 2006).

As massas alimentícias fazem parte da dieta do brasileiro, sendo, portanto, um alimento adequado para ser enriquecido, objetivando o aumento do valor nutricional e melhoramento funcional. Muitos estudos mostram elaboração de massas alimentícias com adição de farinhas das mais variadas fontes. Mariusso (2008) desenvolveu formulação de macarrão fresco enriquecido com farinha de soja desengordurada, oferecendo alternativa para uso de subprodutos agroindustriais. Del Bem et al. (2012) substituiu parcialmente a semolina por farinhas de leguminosas (de ervilha e de grão de bico) na produção de massas alimentícias.

Com base nessas perspectivas e na potencial redução de descartes industriais, o maracujá tem sido utilizado nas formulações de diferentes produtos. A fruta pode ser consumida in natura, porém sua maior importância econômica está na utilização para fins industriais: fabricação de suco integral, néctar e suco concentrado (SENA et al., 2009).

O Brasil é líder mundial na produção de maracujá. Dados da Embrapa mostram que a produção brasileira em 2010 foi de 920 mil toneladas, cerca de $70 \%$ da produção mundial (BRASIL..., 2014). Alguns autores afirmam que o pericarpo e as sementes constituem $65 \%$ desse, descartados como resíduo ou lixo industrial (SENA et al., 2009).
O maracujá (Passiflora edulis flavicarpa) é constituído por $52 \%$ de casca, $34 \%$ de suco e $14 \%$ de semente. A farinha das fibras do maracujá proveniente do resíduo do maracujá amarelo é rica em fibras alimentares (40,2\% base seca), apresentando-se como alternativa para emprego em dietas que necessitem desse complemento. A farinha da casca do maracujá é rica em pectina, uma fração de fibra solúvel que tem a capacidade de reter água formando géis viscosos que retardam o esvaziamento gástrico e o trânsito intestinal (ZERAIK et al., 2010).

Este trabalho teve como objetivo avaliar a influência da substituição parcial da farinha de trigo por farinha de casca de maracujá, rica em fibras e emulsificante, nas características físico-químicas e sensoriais da massa alimentícia.

\section{Material e métodos}

Foi utilizada farinha de trigo especial do Moinho Anaconda, com ferro e ácido fólico, e nenhuma outra aditivação (Tabela 1).

Os resultados do alveograma, $P / L=0,95 \mathrm{e}$ $\mathrm{W}\left(\mathrm{J} \times 10^{-4}\right)=242$, são característicos de farinha de trigo do tipo especial.

Farinha de casca de maracujá fornecida pela Embrapa. Amostras não comercializadas, em embalagens de 250 gramas de Esterlac (estearoil-2-lactil-lactato de sódio) fornecidos pela Purac Sínteses Ind. e Com. Ltda.

Para a obtenção das formulações (padrão e adicionada de farinha de casca de maracujá) foram realizados testes preliminares na planta piloto de Engenharia de Alimentos da Escola de Engenharia Mauá. Para definir a formulação padrão foram testadas duas concentrações de emulsificante (Esterlac), 0,40\% e 0,50\% sobre a farinha de trigo, recomendados pela indústria e dentro do limite permitido pela legislação (0,00\% a 0,50\%

Tabela 1. Resultados das análises físico-químicas e reológicas para a farinha de trigo.

\begin{tabular}{lc}
\multicolumn{1}{c}{ Parâmetros } & Resultado \\
\hline Umidade (\%) & 13,30 \\
Cinzas (\%) & 0,60 \\
Cor L & 93,51 \\
Cor KJ & 0,22 \\
Falling Number (s) & 390 \\
Glúten úmido (\%) & 28,19 \\
P (mm $\left.\mathrm{H}_{2} \mathrm{O}\right)$ & 82 \\
$\mathrm{~L}(\mathrm{~mm})$ & 86 \\
$\mathrm{G}$ & 20,6 \\
$\mathrm{P} / \mathrm{L}$ & 0,95 \\
W (Jx10-4) & 242 \\
le (\%) & 56,1 \\
\hline
\end{tabular}

Fonte: Laudo de análises do Moinho Anaconda. 
sobre a farinha) - Resolução RDC n 60, de 5 de setembro de 2007 (BRASIL, 2007).

Foi usado um delineamento fatorial $2^{2}$, ou seja, dois fatores em dois níveis, resultando um total de quatro formulações. O delineamento foi feito com repetição (em duplicata para cada formulação) e os oito testes foram realizados aleatoriamente, para estabelecer formulação com farinha de casca de maracujá de melhor aceitação.

Foram estabelecidos pontos de máximo $(+1)$ e mínimo $(-1)$ para cada variável independente, a partir dos testes preliminares e limites da legislação RDC n 60, de 5 de setembro de 2007 (BRASIL, 2007). A concentração, sobre a farinha de trigo, variou de $0,20 \%$ a $0,40 \%$ para o emulsificante (Esterlac) e de 5\% a $8 \%$ para a farinha de casca de maracujá.

Os ensaios foram realizados aleatoriamente e em duplicatas seguindo a matriz do planejamento mostrado na Tabela 2 e as medidas das variáveis dependentes foram avaliadas pela Análise de Variância (ANOVA) usando-se o programa Minitab 16.1 (software MINITAB de Estatística e Controle Estatístico de Qualidade).

\subsection{Processo de fabricação da massa alimentícia}

Todos os ingredientes secos foram misturados em uma batedeira Arno Planetária (Modelo BPA) em baixa velocidade por cinco minutos, para a completa homogeneização. Em seguida adicionou-se 38,4\% de água, sobre a farinha de trigo, para obtenção de uma mistura homogênea (10 minutos). A massa obtida foi modelada manualmente, embalada em filme plástico e mantida em repouso por 30 minutos. Em seguida foi laminada e cortada com cilindro de massa da marca Excelsa, em formato de talharim, e permaneceu em estufa com circulação de ar MA037 da marca Marconi, por 15 minutos, a $25{ }^{\circ} \mathrm{C}$, para remoção do excesso de umidade.

\subsection{Avaliação da massa alimentícia}

As massas obtidas, seguindo o delineamento, foram avaliadas por testes de cozimento [descritos pelos métodos 16-50 da AACC (2000)] e de elasticidade. 1 - Tempo de cozimento (em minutos); 2 - Absorção de água: A absorção de água foi determinada pelo aumento de peso ocorrido durante o cozimento (massa do macarrão cozido/massa macarrão cru) × 100 (expresso em \%); 3 - Aumento de volume: 0 aumento do volume foi determinado pelo volume de água deslocado por $10 \mathrm{~g}$ de macarrão antes e depois do cozimento (volume de água deslocado do macarrão cozido/volume de água deslocado do macarrão cru) × 100 (expresso em \%); 4 - Perda de sólidos solúveis: Dada pela porcentagem de sólidos solúveis presentes na água de cozimento; 5 - Elasticidade: Força máxima de ruptura da massa, utilizando-se o aparelho Texturômetro TA-XT2i - Stable Micro Systems com o corpo de prova A/SPR (SMS, 1995). Amostras de massa, cortadas com $30 \mathrm{~cm}$ de comprimento e cozidas, conforme descrito no teste de cozimento, foram lavadas com $150 \mathrm{ml}$ de água destilada e mantidas em repouso por 10 minutos antes da realização das leituras. As seguintes condições operacionais foram observadas: medida de força em tensão $(\mathrm{g})$, velocidade pré-teste $(1,00 \mathrm{~mm} / \mathrm{s})$; velocidade de teste $(3,00 \mathrm{~mm} / \mathrm{s})$; velocidade pós-teste $(10,00 \mathrm{~mm} / \mathrm{s})$; distância (60,00 mm), sensibilidade do equipamento $5 \mathrm{~g}$; e corpo de prova A/SPR.

\subsection{Avaliação sensorial das massas no Laboratório de Análise Sensorial do Instituto Mauá de Tecnologia}

A análise foi realizada com 79 provadores não treinados, estudantes universitários dos cursos de graduação e pós-graduação e funcionários do instituto. As amostras foram codificadas com algarismos de três dígitos (DUTCOSKI, 1996), oferecidas em blocos completos, casualizados e balanceados (MACFIE et al., 1989). Para o teste afetivo foi utilizada escala hedônica estruturada de nove pontos, variando de 1 a 9: 1 - desgostei muitíssimo e 9 - gostei muitíssimo (MEILGAARD et al., 1991), avaliando a aceitação global. Na ficha do teste afetivo de escala hedônica também foi analisada a intenção de compra dos produtos, sendo apresentadas as respostas: sim, não ou talvez comprariam o produto.

Os dados, obtidos por meio de ficha de avaliação foram submetidos à análise estatística; no teste sensorial afetivo foi aplicada a análise de variância (ANOVA), ao nível de significância de 5\% (ARANGO, 2005).

Tabela 2. Matriz de ensaios para o planejamento fatorial.

\begin{tabular}{|c|c|c|c|c|}
\hline \multirow{2}{*}{ Ensaios } & \multicolumn{2}{|c|}{ Variáveis codificadas } & \multicolumn{2}{|c|}{ Variáveis originais $\left({ }^{*}\right)$} \\
\hline & A & B & Esterlac & Farinha de maracujá \\
\hline 1 & -1 & -1 & 0,2 & 5 \\
\hline 2 & +1 & -1 & 0,4 & 5 \\
\hline 3 & -1 & +1 & 0,2 & 8 \\
\hline 4 & +1 & +1 & 0,4 & 8 \\
\hline
\end{tabular}

*Valores apresentados em \% sobre a farinha de trigo. 


\section{Resultados e discussão}

Para definição da formulação da massa fresca padrão foram feitos testes. As massas foram cortadas no formato de talharim, embaladas em saco plástico e armazenada em câmara fria $\left(4^{\circ} \mathrm{C}\right)$. Após 12 horas de armazenamento apresentaram uma coloração esverdeada, que foi resolvida após a pré-secagem da massa modelada, por 15 minutos, a $25^{\circ} \mathrm{C}$, em estufa com circulação de ar (Figura 1). Em seguida, a massa foi embalada em sacos plásticos e armazenada na câmara fria $\left(4^{\circ} \mathrm{C}\right)$.

Como a cor final da massa fresca após a retirada parcial de umidade apresentou-se característica, a formulação padrão final foi definida: $100 \%$ de farinha de trigo, 38,4\% de água e 0,40\% de emulsificante (\% sobre a farinha de trigo).

Foram realizados todos os testes de cozimento: coeficiente de absorção de água, tempo de cozimento, coeficiente de aumento de volume, \% de perda de sólidos solúveis e elasticidade (Tabela 3).

Segundo os critérios de Hummel (1966), perda de sólidos solúveis de até $6 \%$ é característica de massa de trigo de qualidade muito boa, de até $8 \%$, de massa de média qualidade, e de valores iguais ou superiores a 10\%, é característica de massa de baixa qualidade. Portanto a qualidade do macarrão obtido foi muito boa quando avaliada a perda de sólidos.

Para a substituição parcial da farinha de trigo por farinha de casca de maracujá foi necessário acertar a granulometria das farinhas para se obter melhor homogeneização na mistura. Ambas foram peneiradas: a farinha retida na peneira de $355 \mu \mathrm{m}$ (45 mesh) foi descartada e a parte passante, utilizada para a produção do macarrão.

Avaliando-se os resultados preliminares, concluiu-se que massas produzidas com substituição superior a $8 \%$ de farinha de trigo por farinha de casca de maracujá ficaram quebradiças durante o cozimento, impossibilitando a realização de quaisquer testes de qualidade da massa. E que substituições inferiores a $5 \%$ não produziriam massas classificadas como fonte de fibras. A faixa para adição de emulsificante ficou estabelecida entre $0,2 \%$ e $0,4 \%$ (máximo permitido pela legislação). Os resultados dos ensaios estabelecidos pelo delineamento estão na Tabela 3.

Por meio do programa estatístico Minitab obtiveram-se os coeficientes de regressão, apresentados na Tabela 4 - análise do modelo por meio da ANOVA, para cálculo dos desvios e gráficos.
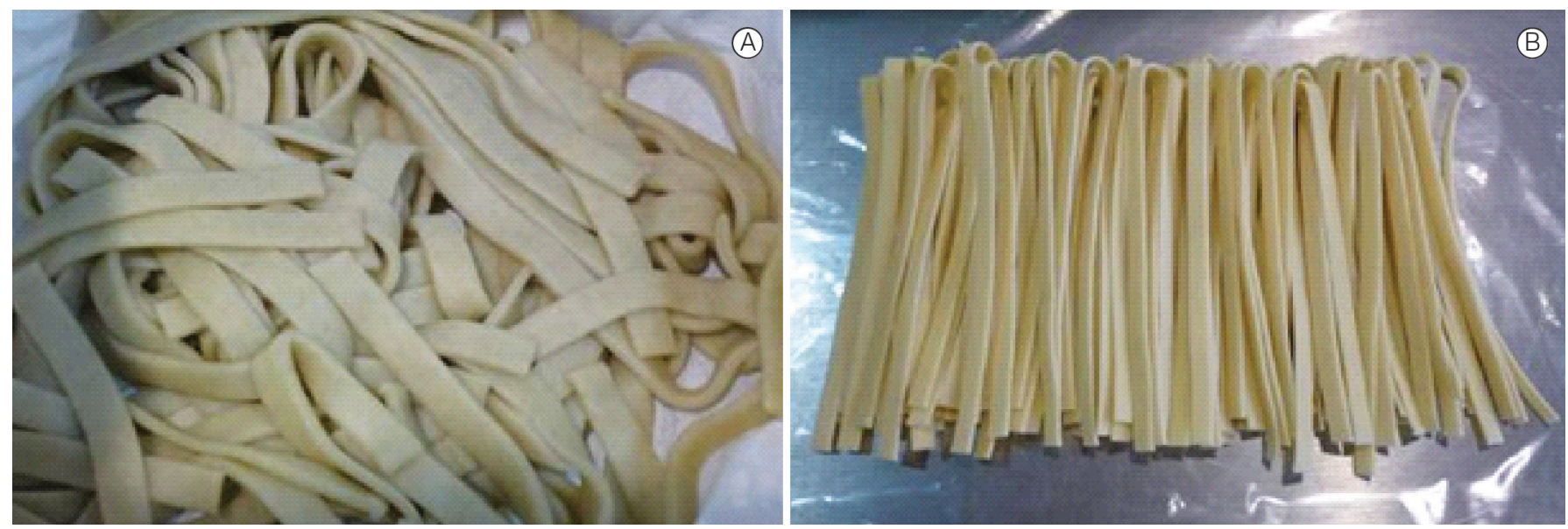

Figura 1. A - Massa fresca esverdeada; B - Massa fresca padrão, após permanência em estufa.

Tabela 3. Resultados dos ensaios estabelecidos no delineamento para tempo de cozimento, coeficiente de absorção de água, coeficiente de aumento de volume, perda de sólidos e elasticidade das massas adicionadas de farinha de casca de maracujá e Esterlac.

\begin{tabular}{ccccccccc} 
Ensaios & $\begin{array}{c}\text { Esterlac } \\
(\%)\end{array}$ & $\begin{array}{c}\text { Farinha de } \\
\text { casca de } \\
\text { maracujá (\%) }\end{array}$ & $\begin{array}{c}\text { Tempo de } \\
\text { cozimento } \\
(\mathbf{m i n})\end{array}$ & $\begin{array}{c}\text { Absorção de } \\
\text { água (\%) }\end{array}$ & $\begin{array}{c}\text { Aumento de } \\
\text { volume (\%) }\end{array}$ & $\begin{array}{c}\text { Perda de } \\
\text { sólidos (\%) }\end{array}$ & $\begin{array}{c}\text { Elasticidade - Força } \\
\text { de ruptura (N) }\end{array}$ \\
\hline 1 & 0,2 & 5,0 & $8: 30$ & $1,96 \pm 0,08$ & $1,39 \pm 0,03$ & $7,03 \pm 0,09$ & $0,39 \pm 0,02$ \\
2 & 0,4 & 5,0 & $8: 15$ & $2,06 \pm 0,08$ & $1,40 \pm 0,04$ & $6,01 \pm 00,1$ & $0,44 \pm 0,02$ \\
3 & 0,2 & 8,0 & $9: 00$ & $2,0 \pm 0,1$ & $1,37 \pm 0,05$ & $8,4 \pm 0,6$ & $0,37 \pm 0,04$ \\
4 & 0,4 & 8,0 & $8: 30$ & $1,98 \pm 0,02$ & $1,37 \pm 0,05$ & $8,1 \pm 0,8$ & $0,38 \pm 0,03$ \\
\hline
\end{tabular}

Massas com adição de farinha de casca de maracujá e emulsificante Esterlac; todos os resultados são média de seis valores, exceto a elasticidade, que é média de 17 repetições. 
Todos os termos da regressão para absorção de água e aumento de volume foram excluídos (Tabela 4), pois os efeitos nesses pontos não foram estatisticamente significativos $(p>0,05)$ para os termos ou para as interações, ou seja, a absorção de água e o aumento de volume não foram afetados pelas formulações. Não houve diferença entre as medidas apresentadas pelas massas das formulações definidas pelo planejamento.

Os termos da regressão esterlac (A) e Esterlac*farinha da casca de maracujá $\left(A^{\star} B\right)$ para perda de sólidos e elasticidade foram excluídos (Tabela 4), pois os efeitos nesses pontos não foram estatisticamente significativos $(p>0,05)$. Para o termo farinha da casca de maracujá (B), a perda de sólidos e a elasticidade foram afetadas nas condições analisadas. Como a distribuição dos dados segue uma distribuição normal e a distribuição aleatória mostrou que a ordem de realização dos ensaios não interferiu nos resultados (Figura 2), é possível avaliar a curva de efeitos para a perda de sólidos e a elasticidade.

A variação na concentração do Esterlac, de 0,2\% a 0,4\%, não afetou a perda de sólidos e a elasticidade da massa, porém a variação da concentração de farinha da casca do maracujá de $5 \%$ para $8 \%$ afetou positivamente a perda de sólidos e negativamente a elasticidade, ou seja, quanto maior a concentração da farinha de casca de maracujá, maior será a perda de sólidos e menor será a elasticidade, independentemente da concentração do emulsificante.

Avaliando-se os resultados das massas obtidos nos ensaios definidos pelo delineamento experimental para todos os parâmetros avaliados, a formulação que mais se aproximou da formulação padrão (MP) foi aquela com $5 \%$ de farinha de casca de maracujá e $0,4 \%$ de Esterlac (MCE). Os resultados comparando as duas formulações estão na Tabela 5.
Os resultados apresentados na Tabela 5 indicam que o tempo de cozimento da massa padrão (MP) foi menor $(p<0,05)$ quando comparado com o da massa adicionada de Esterlac (MCE). Esses resultados diferem daqueles obtidos por Barbosa (2002), porém deve-se levar em consideração que no produto por ele avaliado a substituição foi feita com farinha de soja e não de maracujá.

O tempo de cozimento tem um efeito significativo sobre a absorção de água e a perda de sólidos solúveis em massas alimentícias. Reinhard et al. (2004) observaram que quanto maior o tempo de cozimento maior serão a absorção de água e a perda de sólidos solúveis das massas alimentícias.

Nielsen et al. (1980), citado por Bahnassey e Khan (1986), encontraram uma reduzida absorção de água para espaguete contendo $33 \%$ de farinha de ervilha ou $20 \%$ de concentrado proteico de ervilha. Bahnassey e Khan (1986) também encontraram que a absorção de água de espaguete fortificado com vários níveis de farinhas de leguminosas diminuiu à medida que se aumentou 0 nível de fortificação.

Ormenese et al. (2004) avaliaram massas alimentícias com ovos, observando aumentos de volume na faixa de 1,19 e 1,42, valores esses semelhantes aos observados para a massa adicionada de Esterlac e farinha da casca de maracujá - valores entre 1,37 e 1,40 (Tabela 3).

Ormenese e Chang (2003) avaliaram macarrão de arroz e de trigo, em que observaram perda de sólidos solúveis de $6 \%$ na massa de trigo e $5,9 \%$ na de arroz, valores semelhantes aos da massa adicionada de farinha de casca do maracujá, de 6,01\%.

Tabela 4. Parâmetros da regressão para a absorção de água, aumento de volume, perda de sólidos e elasticidade.

\begin{tabular}{|c|c|c|c|c|c|c|c|c|}
\hline \multirow[t]{2}{*}{ Termos } & \multicolumn{2}{|c|}{ Absorção de água } & \multicolumn{2}{|c|}{ Aumento de volume } & \multicolumn{2}{|c|}{ Perda de sólidos } & \multicolumn{2}{|c|}{ Elasticidade } \\
\hline & Efeitos & $\mathbf{P}$ & Efeitos & $\mathbf{P}$ & Efeitos & $\mathbf{P}$ & Efeitos & $\mathbf{P}$ \\
\hline Constante & & 0,000 & & 0,0000 & & 0,000 & & 0,000 \\
\hline A & 0,03437 & 0,562 & 0,00500 & 0,8970 & $-0,5001$ & 0,348 & 0,01240 & 0,179 \\
\hline B & $-0,01838$ & 0,753 & $-0,02000$ & 0,6100 & 2,0993 & 0,011 & $-0,02280$ & 0,040 \\
\hline$A^{*} B$ & $-0,06048$ & 0,329 & $-0,00000$ & 1,0000 & $-0,0217$ & 0,965 & 0,004450 & 0,590 \\
\hline
\end{tabular}

A - Esterlac; B - farinha da casca do maracujá.

Tabela 5. Resultados para tempo de cozimento, coeficiente de absorção de água, coeficiente de aumento de volume, perda de sólidos e elasticidade da massa padrão e da massa com $5 \%$ de farinha de casca de maracujá e 0,4\% de Esterlac.

\begin{tabular}{ccccccccc} 
Amostra & Esterlac (\%) & $\begin{array}{c}\text { Farinha de } \\
\text { casca de } \\
\text { maracujá }(\%)\end{array}$ & $\begin{array}{c}\text { Tempo de } \\
\text { cozimento } \\
(\mathbf{m i n})\end{array}$ & $\begin{array}{c}\text { Coeficiente } \\
\text { de absorção } \\
\text { de água }\end{array}$ & $\begin{array}{c}\text { Coeficiente } \\
\text { de aumento } \\
\text { de volume }\end{array}$ & $\begin{array}{c}\text { Perda de } \\
\text { sólidos (\%) }\end{array}$ & $\begin{array}{c}\text { Elasticidade - Força } \\
\text { de ruptura (N) }\end{array}$ \\
MP & 0,4 & - & $7: 30$ & $1,88 \pm 0,3^{\mathrm{a}}$ & $1,45 \pm 0,05^{\mathrm{a}}$ & $3,4 \pm 0,3^{\mathrm{a}}$ & $0,51 \pm 0,03^{\mathrm{a}}$ \\
MCE & 0,4 & 5,0 & $8: 15$ & $2,06 \pm 0,08^{\mathrm{a}}$ & $1,40 \pm 0,04^{\mathrm{a}}$ & $6,01 \pm 0,1^{\mathrm{b}}$ & $0,44 \pm 0,02^{\mathrm{b}}$ \\
\hline
\end{tabular}

MP - massa padrão; MCE - massa com adição de farinha de casca de maracujá e emulsificante Esterlac; todos os resultados são médias de seis valores, exceto a elasticidade, que é média de 17 repetições; médias com letras diferentes na mesma coluna diferem estatisticamente ao nível de $5 \%$ de significância. 


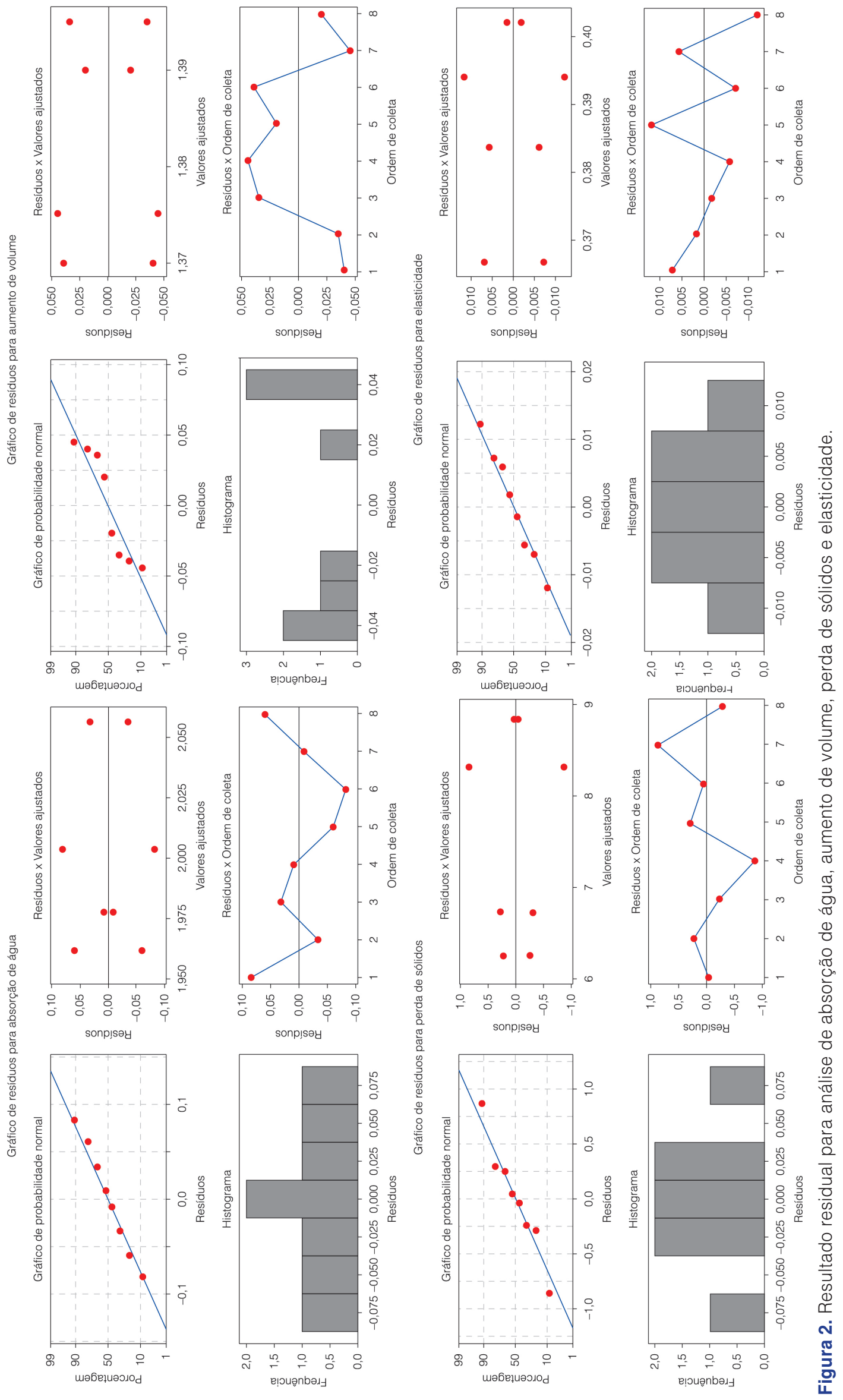


Tabela 6. Média das notas atribuídas às amostras de massa padrão (MP) e massa com 0,4\% de Esterlac e $5 \%$ de farinha da casca do maracujá (MCE) na análise sensorial.

\begin{tabular}{cc} 
Amostra & Média* $^{*}$ \\
MP & $7,59^{a}$ \\
MCE & $7,37^{\mathrm{a}}$ \\
\hline
\end{tabular}

*Médias com letras iguais na mesma coluna não diferem estatisticamente ao nível de 5\% de significância.

Macarrão misto de farinha de trigo e farinha de feijão guandu foi avaliado por Casagrandi et al. (1999). Os autores observaram $9,2 \%$ de perda de sólidos solúveis na massa com $100 \%$ de trigo e $15,6 \%$ na massa com $15 \%$ de farinha de feijão guandu.

Del Bem et al. (2012) observaram perda de sólidos de 7,7\% em massa alimentícia adicionada de farinha de ervilha e de $7,9 \%$ em massa adicionada de farinha de grão de bico.

Uma alternativa bastante estudada de redução da perda de sólidos solúveis na água de cozimento de massa alimentícia é o uso de emulsificante. Os emulsificantes atuam melhorando a tolerância das massas ao cozimento, dando-se a sua ação tanto pelo fortalecimento de interações da cadeia de proteínas que formam o glúten, produzindo uma matriz proteica mais forte, quanto na formação de complexos com a amilose, fração linear do amido, que reduz o escape dela para a água de cozimento durante o fenômeno da gelatinização (CICHELLO et al., 2000).

Ormenese et al. (2004), comparando o efeito da adição de emulsificantes monoglicerídeos destilados (MGD) e estearoil-2-lactil lactato de sódio nas características de cozimento de massas alimentícias de arroz obtidas por processo convencional, verificaram que tanto o emulsificante de monoglicerídeos quanto o estearoil2-lactil lactato de sódio reduziram condicionalmente a perda de sólidos solúveis $(7,8 \%$ e $8,5 \%$, respectivamente) contra $17,1 \%$ para a massa sem aditivo.

Análises sensoriais com massa padrão (MP) e com a massa contendo $0,4 \%$ de Esterlac e $5 \%$ de farinha de maracujá (MCE) foram realizadas com 79 provadores, $72 \%$ do sexo feminino e $28 \%$ do sexo masculino, na faixa etária de 17 a 55 anos. A média das notas atribuídas para as amostras estão entre "Gostei regularmente" e "Gostei muito" da escala hedônica (Tabela 6 e Figura 3).

A massa padrão (MP) e a massa contendo 0,4\% de Esterlac e $5 \%$ de farinha de casca de maracujá (MCE) tiveram uma boa intenção de compra (Figura 4).

As amostras não apresentaram diferenças significativas $(p>0,05)$ entre a MP e a MCE, o que indica que não houve preferência.

A composição química centesimal da massa com $0,4 \%$ de Esterlac e $5 \%$ de farinha de maracujá (MCE) está apresentada no Tabela 7. Como o teor de fibras é superior a $3 \%$, pode-se considerar que a massa é fonte de fibras (2,5 gramas na porção de 80 gramas, referente à medida caseira de um prato de macarrão), conforme o Regulamento Técnico sobre Informação Nutricional Complementar - Resolução RDC n 54, de 12 de novembro de 2012 (BRASIL, 2012).

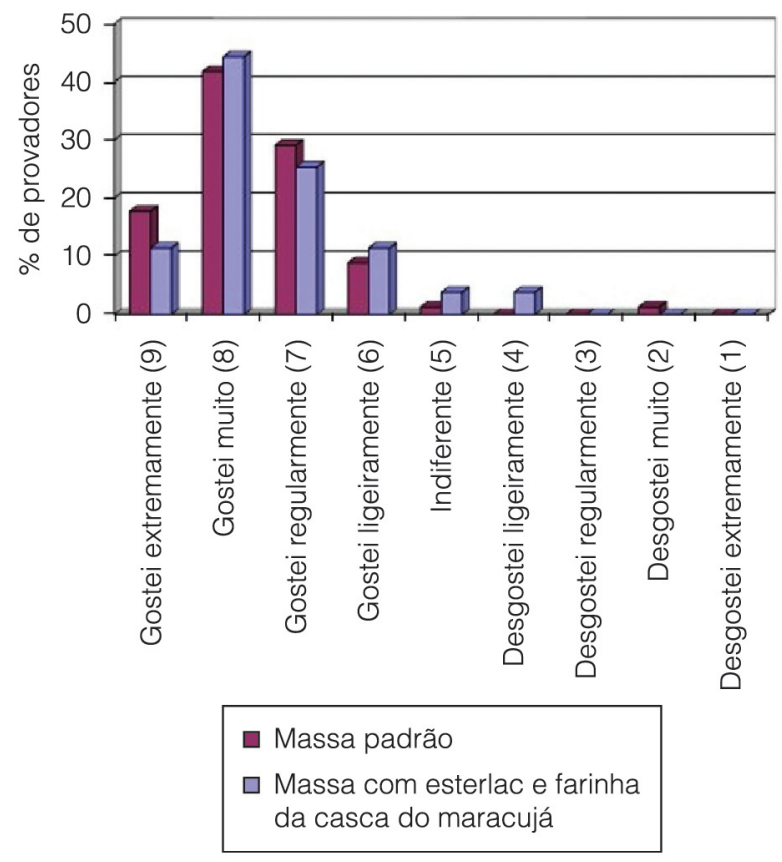

Figura 3. Notas atribuídas pelos provadores ao produto.

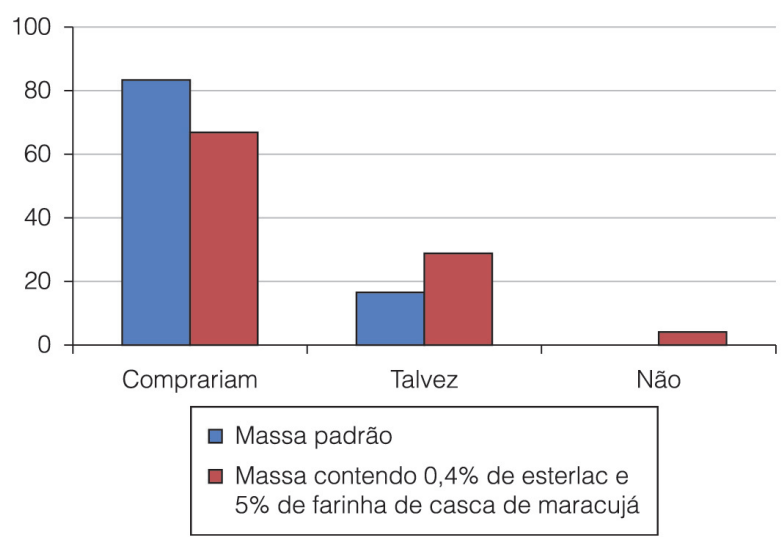

Figura 4. Intenção de compra para a massa padrão (MP) e para a massa contendo $0,4 \%$ de Esterlac e $5 \%$ de farinha de casca de maracujá (MCE).

Tabela 7. Composição centesimal da massa contendo $0,4 \%$ de Esterlac e $5 \%$ de farinha de casca de maracujá.

\begin{tabular}{lc} 
& $\%$ (relação mássica) \\
\hline Carboidratos & 52,45 \\
Cinzas & 0,61 \\
Gordura total & 1,34 \\
Ácidos graxos saturados & 0,99 \\
Ácidos graxos trans & $<0,06$ \\
Proteína & 9,25 \\
Umidade & 31,13 \\
Sódio & 0,0598 \\
Fibra alimentar & 5,22 \\
Valor energético & $258,86 \mathrm{kcal} / 100 \mathrm{~g}$ \\
\hline
\end{tabular}

Fonte: Análises realizadas na massa cozida do macarrão pelo laboratório Bioagri Análise de Alimentos Ltda. 


\section{Conclusões}

A formulação final (adicionada de farinha de casca de maracujá) para a massa de macarrão foi estabelecida como $0,4 \%$ de emulsificante estearoil-2-lactil-lactato de sódio e $5 \%$ de farinha de casca de maracujá (MCE). Esses percentuais de emulsificante e farinha de casca de maracujá foram determinados por meio dos resultados da absorção de água, aumento de volume, perda de sólidos e elasticidade que mais se aproximaram dos da massa padrão, massa com 0,4\% de emulsificante e sem adição da farinha da casca do maracujá.

$\mathrm{Na}$ análise sensorial não houve diferença significativa $(p>0,05)$ entre a massa padrão e a massa adicionada de farinha de casca de maracujá e emulsificante, o que indica que não houve preferência.

A composição centesimal mostrou que a massa contendo $0,4 \%$ de emulsificante e $5 \%$ de farinha de casca de maracujá (MCE) é fonte de fibras, pois o valor de fibras é superior a 3\% e a 2,5 gramas na porção de 80 gramas, referente à medida caseira de um prato de macarrão.

\section{Agradecimentos}

Ao Instituto Mauá de Tecnologia (IMT), à Purac Sínteses, pela doação do emulsificante, e à Empresa Brasileira de Pesquisa Agropecuária (Embrapa), pelo fornecimento da farinha de maracujá.

\section{Referências}

AMERICAN ASSOCIATION OF CEREAL CHEMISTS - AACC. Approved Methods. 10th ed. Saint Paul: AACC, 2000.

ARANGO, H. G. Bioestatística Teórica e Computacional. 2. ed. Rio de Janeiro: Guanabara Koogan, 2005. 423 p.

BAHNASSEY, Y.; KHAN, K. Fortification of Spaghetti with Edible Legumes. II. Rheological, Processing, and Quality Evaluation Studies. Cereal Chemistry, Saint Paul, v. 63, n. 3, p. 216-219, 1986.

BARBOSA, M. C. A. Avaliação Tecnológica de Massas Alimentícias de Farinha Mista de Trigo e Soja sem Lipoxigenases. 2002. 100 f. Tese (Doutorado em Ciência e Tecnologia de Alimentos)-Universidade Federal de Viçosa, Viçosa, 2002.

BRASIL. Agência Nacional de Vigilância Sanitária. Resolução RDC $n^{\circ}$ 60, de 05 de setembro de 2007. Regulamento Técnico sobre Atribuição de Aditivos e seus Limites Máximos para a Categoria de Alimentos 6: Cereais e Produtos de ou a Base de Cereais. Diário Oficial da União, Poder Executivo, DF, Brasília, 11 set. 2007. Disponível em: <http://www.anvisa.gov.br>. Acesso em: 17 ago. 2013.

BRASIL. Agência Nacional de Vigilância Sanitária. Resolução RDC $n^{\circ}$ 54, de 12 de novembro de 2012. Dispõe sobre
- Regulamento Técnico sobre Informação Nutricional Complementar. Diário Oficial da União, Poder Executivo, DF, Brasília, 13 nov. 2012. Disponível em: <http://www.anvisa.gov. br>. Acesso em: 17 ago. 2013. Seção 1.

BRASIL é Líder Mundial na Produção de Maracujás. Portal Terra: Economia, 25 maio 2013. Disponível em: <http://economia.terra. com.br>. Acesso em: 24 fev. 2014.

CASAGRANDI, D. A.; CANNIATTI-BRAZACA, S. G.; SALGADO, J. M.; PIZZINATO, A.; NOVAES, N. J. Análise Tecnológica, Nutricional e Sensorial de Macarrão Elaborado com Farinha de Trigo Adicionada de Farinha de Feijão Guandu. Revista de Nutrição, Campinas, v. 12, n. 2, p. 137-143, 1999.

CICHELLO, M. S. F.; PAVANELLI, A. P.; PALMA, E. J.; ANDRADE, M. A. Alternativas de Emulsificantes para a Qualidade de Massas Alimentícias. São Paulo: Oxiteno S/A Indústria e Comércio, 2000. 10 p.

DEL BEM, M. S.; POLESI, L. F.; SARMENTO, S. B. S.; ANJOS, C. B. P. Propriedades Físico-químicas e Sensoriais de Massas Alimentícias Elaboradas com Farinhas de Leguminosas Tratadas Hidrotermicamente. Alimentos e Nutrição, Araraquara, v. 23, n. 1, p. 101-110, 2012.

DUTCOSKI, S. D. Análise Sensorial de Alimentos. Paraná: Universitária Champagnat, 1996. 123 p.

GUERREIRO, L. Dossiê Técnico de Massas Alimentícias. Rio de Janeiro: Rede de Tecnologia do Rio de Janeiro, 2006. 39 p.

HUMMEL, C. Macaroni Products: Manufacture, Processing and Packing. 2nd ed. London: Food Trade, 1966. 287 p.

MARIUSSO, A. C. B. Estudo do Enriquecimento de Massas Alimentícias com Subprodutos Agroindustriais Visando o Melhoramento Funcional e Tecnológico de Massas Frescas. 2008. 100 f. Dissertação (Mestrado em Ciência dos Alimentos)Faculdade de Engenharia de Alimentos, Universidade Estadual de Campinas, Campinas, 2008.

MACFIE, H. J.; BRATCHELL, N.; GREENHOFF, K.; VALLIS, L. V. Designs to Balance the Effect of Order of Presentation and First-order Carry-over Effects in Hall Tests. Journal of Sensory Studies, Trumbull, v. 4, n. 2, p. 129-148, 1989.

MEILGAARD, M.; CIVILLE, G. V.; CARR, B. T. Sensory Evaluation Techniques. 2nd ed. London: CRC Press, 1991. 354 p.

MENEGASSI, B.; LEONEL, M. Análises de Qualidade de uma Massa Alimentícia Mista de Mandioquinha-salsa. Revista Raízes e Amidos Tropicais, Botucatu, v. 2, p. 27-36, 2006.

NIELSEN, M. A.; SUMMER, A. K.; WHALLEY, L. L. Fortification of Pasta with Pea Flour and Air Classified Pea Protein Concentrate. Cereal Chemistry, Saint Paul, v. 57, n. 3, p. 203-206, 1980.

ORMENESE, R. C. S. C. Influência da Adição de Emulsificantes nas Características de Cozimento do Macarrão de Arroz Obtido pelo Processo Convencional de Produção de Massas 
Aplicação de farinha de casca de maracujá em massa alimentícia fresca

FOGAGNOLI, G. e SERAVALLI, E. A. G.

Alimentícias. In: CONGRESSO BRASILEIRO DE CIÊNCIA E TECNOlogiA DE ALIMENTOS-CBCtA, Poços de Caldas, 1996. p. 747-757 (v.2).

ORMENESE, R. C. S. C.; CHANG, Y. K. Macarrão de Arroz: Características de Cozimento e Textura e Comparação com o Macarrão Convencional e Aceitação pelo Consumidor. Brazilian Journal Food Technology, Campinas, v. 6, n. 1, p. 91-97, 2003.

ORMENESE, R. C. S. C.; MISUMI, L.; ZAMBRANO, F.; FARIA, E. V. Influência do Uso de Ovo Líquido Pasteurizado e Ovo Desidratado nas Características da Massa Alimentícia. Ciência e Tecnologia de Alimentos, Campinas, v. 24, n. 2, p. 255-260, 2004. http://dx.doi.org/10.1590/S0101-20612004000200016

REINHARD, W. D.; KHAN, K.; DICK, J. W.; HOLM, Y. Shelf Life Stability of Spaghetti Fortified with Legumes Flours and Protein
Concentrate. Cereal Chemistry, Saint Paul, v. 65, n. 4, p. 278-281, 1988.

SENA, L. M.; ZUCOLOTTO, S. M.; REGINATTO, F. H.; SCHENKEL, E. P.; LIMA, T. C. M. Neuropharmacological Activity of the Pericarpo of Passiflora edulis flavicarpa Degener: Putative Involvement of C-glycosylflavonoids. Experimental Biology and Medicine, Maywood, v. 234, n. 8, p. 967-975, 2009. PMid:19491371. http://dx.doi.org/10.3181/0902-RM-84

STABLE MICRO SYSTEMS - SMS. Extensibility of Dough and Measure of Gluten Quality (TA-XT2 Application Study REF: DOU/KIE). Surrey: Stable Micro Systems, 1995.

ZERAIK, M. L.; PEREIRA, C. A. M.; ZUIN, V. G.; YARIWAKE, J. H. Maracujá: um Alimento Funcional? Revista Brasileira de Farmacognosia, São Paulo, v. 20, n. 3, p. 459-471, 2010. http:// dx.doi.org/10.1590/S0102-695X2010000300026 